\title{
FRICTIONAL BEHAVIOR OF DIAMONDLIKE CARBON FILMS IN VACUUM AND UNDER VARYING WATER VAPOR PRESSURE*
}

\author{
J. Andersson, ${ }^{* *}$ R. A. Erck, and A. Erdemir \\ Argonne National Laboratory \\ Energy Technology Division \\ Argonne, IL 60439 \\ **The Angstrom Laboratory \\ Tribomaterials Group \\ Uppsala, SE-751 21
}

\begin{abstract}
The submitted manuscript has been created by the University of Chicago as Operator of Argonne National Laboratory under Contract No. W-31-109-ENG-38 with the U.S.

Department of Energy. The U.S. Government retains for itself, and others acting on its behalf, a paid-up, nonexclusive, irrevocable worldwide license in said article to reproduce, prepare derivative works, distribute copies to the public, and perform publicly and display publicly, by or on behalf of the Government.
\end{abstract}

July 2002

Presented at the International Conference on Metallurgical Coatings and Thin Films, April 21-26, 2002, San Diego, CA.

*Work supported by U.S. Department Energy, Office of Transportation Technologies, under contract W-31-109-Eng-38. 


\title{
FRICTIONAL BEHAVIOR OF DIAMONDLIKE CARBON FILMS IN
}

\section{VACUUM AND UNDER VARYING WATER VAPOR PRESSURE}

\author{
J. Andersson, * R. A. Erck, and A. Erdemir \\ Argonne National Laboratory \\ Energy Technology Division \\ Argonne, IL 60439 \\ USA \\ *The Angstrom Laboratory \\ Tribomaterials Group \\ Uppsala, SE-751 21 \\ Sweden
}

\begin{abstract}
In this study, we investigated the frictional behavior of both hydrogenated and hydrogen-free diamondlike carbon (DLC) films in high vacuum $\left(10^{-6} \mathrm{~Pa}\right)$ at room temperature. Water was also introduced into the vacuum chamber to elucidate its effects on DLC film tribology. The hydrogen-free DLC (also referred to as tetrahedral amorphous carbon, or ta-C) was produced by an arc-PVD process, and the highly hydrogenated DLC was produced by plasma-enhanced chemical-vapor deposition. Tribological measurements of these films were made with a pin-on-disc machine with coated steel balls and coated steel discs in matched pairs under a $1 \mathrm{~N}$ load. The ball/disk pairs were rotated at sliding speeds in the range of $0.025-0.075 \mathrm{~m} / \mathrm{s}$. In vacuum, the steady-state friction coefficient of ta-C was of the order of 0.6 and the wear was severe, whereas for the highly hydrogenated film, friction was below 0.01 , and in an optical microscope no wear could be detected. Adding water vapor to the sliding ta-C system in a vacuum chamber caused friction to decrease monotonically from 0.6 to $\approx 0.05$. In contrast, adding water vapor to the sliding DLC system caused the friction to increase linearly with pressure from 0.01 to 0.07 . The results illustrate the importance of taking into account environmental conditions, especially the presence of water, when DLC films are being considered for a given application.
\end{abstract}




\section{INTRODUCTION}

Many tribological studies have demonstrated that the chemical composition of the test environment plays an important role in the friction and wear performance of most bulk materials (such as metals, polymers, ceramics) and thin solid films. For example, model experiments by Savage on graphite [1] and Bowden and his co-workers [2,3] on diamond in the 1950s and 1960s have clearly shown that moisture or water molecules in the test environment strongly influence the friction and wear behavior of these materials. Further studies on diamond and diamondlike carbon (DLC) films by other researchers $[4,5]$ have also confirmed that the composition of the test environment indeed exerts a strong influence on the frictional behavior of these films. Today, as diamond and DLC films are considered for applications that range from automotive parts to components for space mechanisms further elucidation of the effect of environmental species on friction and wear of these films becomes even more important. In this study, we concentrate on DLC films.

The family of DLC films is quite large and covers a wide range of structures and compositions; hence the properties of these films differ significantly. For example, the films produced by cathodic arc deposition or the laser ablation process consist of pure carbon with very high tetrahedral or $\mathrm{sp}^{3}$ bonding. They are very hard and hence resistant to scratching or abrasive wear. Because of high levels of $\mathrm{sp}^{3}$ bonding between carbon atoms, these films are frequently referred to as tetrahedral amorphous carbon (ta-C) or "amorphous diamond." In an ambient environment, they usually exhibit low friction coefficients and wear very slowly. This behavior is generally believed to be associated with water in the surrounding air [6].

With the advent of highly hydrogenated DLC films, we have, for the first time, hard coatings that provide both exceptionally low friction coefficients and very low wear in vacuum $[7,8]$. Erdemir et al. grew DLC films by plasma enhanced chemical vapor deposition (PE-CVD) with successively higher hydrogen-to-carbon ratios in the source gases [9]. The friction of these films in a dry nitrogen atmosphere has been shown to decrease with increasing amounts of hydrogen the film, and a friction coefficient as low as 0.003 was reported. Donnet et al grew carbon films that 
contained hydrogen by a similar deposition technique [10] and concluded that the films needed to contain at least $40 \%$ hydrogen to give ultralow friction in vacuum. Unfortunately, in a normal atmosphere, these films exhibited considerably higher friction coefficients and wear.

In the past, several researchers have attempted to produce DLC and diamond coatings that exhibit low friction and high wear resistance in a normal atmosphere as well as in vacuum. Voevodin et al. approached the problem with a multiphase $\mathrm{WC} / \mathrm{DLC} / \mathrm{WS}_{2}$ nanocomposite [11]; they were able to keep the friction coefficient below 0.15 for several cycles of alternating nitrogen and moist air. However, the friction increased somewhat for each cycle. Miyoshi [12] reduced the friction of CVD-diamond in vacuum from 1 to less than 0.2 by ion-implantation. Once the transformed surface layer was worn away, the friction returned to 1 . Concentrating on the effect of ambient water, Gilmore and Hauert [13] managed to keep the friction of a DLC film constant at 0.08 under conditions of $5-85 \%$ relative humidity by doping carbon-based films with 4 at.\% silicon. The reduction in friction was attained at the expense of increased wear rate.

Trace constituents in the atmosphere can exert a controlling influence on the friction coefficient. Heimberg et al performed reciprocating pin-on-disc experiments on a highly hydrogenated carbon film in dry nitrogen [14]. By changing the linear velocity of the pin and changing the time between passages with a constant velocity, they concluded that the variation in friction was due to a time-effect rather than a speed effect. The increase in friction with time between consecutive passes could be very well fitted to an adsorption model, indicating that adsorption of some constituent from the atmosphere could be controlling the friction coefficient of their DLC film.

With the long-term goal of producing a low-friction coating that is largely insensitive to cycling between normal atmosphere and vacuum, DLC films, with their flexible chemistry, seem to be an attractive starting point. Clearly, in addition to their composition and microstructure, the tribological performance of DLC films is influenced by ambient gases, and perhaps predominantly so by water vapor. To clarify the frictional dependence on water vapor of carbon-based films in general, and 
ta-C and highly hydrogenated DLC films in particular, one film from each category was put through the experiments presented in this article.

\section{EXPERIMENT}

\section{Materials}

Tetrahedral amorphous carbon was deposited on AISI-H13 steel flats and 9.53-mmdiameter M50 steel balls by cathodic-arc evaporation of a carbon target to a thickness of $\approx 0.5 \mu \mathrm{m}$. Details are available in Ref. 15 . The hydrogen content is expected to be very small.

On the same substrate material, an approximately $1-\mu \mathrm{m}$-thick hydrogenated carbon film (HCF) was produced by PECVD in a 75\% hydrogen, $25 \%$ methane gas mixture. Details of this process are described in Ref. 9. Hydrogen forward scattering measurements using $2 \mathrm{MeV} \mathrm{He}{ }^{++}$ions find the composition to be 39 at.\% $\mathrm{H}$, 61 at. $\% \mathrm{C}$

\section{Equipment and Experiments}

The sliding friction between the coated ball and the similarly coated flat was measured in a rotating pin-on-disc setup. The normal force, applied by tensioning a spring with a micrometer drive, was measured by a strain gauge transducer. A torque transducer measured the lateral force produced by the friction. Both transducers were calibrated by applying weights of known masses.

The pin-on-disc experiments were conducted in a vacuum chamber capable of maintaining a pressure of $1 * 10^{-6} \mathrm{~Pa}$ and equipped with a residual-gas analyzer. A highpurity-gas introduction system facilitated the creation of argon, nitrogen, hydrogen or oxygen atmospheres. An open tube with a valve allowed the introduction of water or any other liquid into the vacuum chamber.

The samples were cleaned before the experiments, first ultrasonically in acetone and then in ethanol, and finally blown dry with compressed air. For the experiments, a normal force of $1 \mathrm{~N}$ was applied. The zero-level was recorded for some time, usually $20 \mathrm{~s}$, and then the rotation was initiated. A constant rotational frequency of 60 RPM, 
corresponding to a linear velocity in the range of $0.025-0.075 \mathrm{~m} / \mathrm{s}$, was used in all of the experiments. The duration of each test was $\approx 100$ revolutions. Tests at various sliding radii could be made without breaking the vacuum by shifting the position of the rotating disk with respect to the ball holder by using a micrometer drive. Balls could be exchanged through a vacuum load lock so the worn surface could be examined and oriented to an unworn position.

Friction was first measured at $5 * 10^{-6} \mathrm{~Pa}$ for each material and the balls were removed for inspection. After the vacuum tests, the chamber was backfilled with water to various pressures. The introduction of small quantities of water readily led to a stable pressure. However, when even more water was added to bring the chamber up to near the vapor pressure at room temperature $(\approx 2500 \mathrm{~Pa})$, equilibrium was reached rather gradually. Intermittently, the chamber was pumped out and new experiments were conducted at lower pressures and then water was again added. This procedure was repeated several times to guarantee repeatability and to obtain data at several pressures. All experiments with added water were performed in the same track and on the same contact spot on the ball.

\section{RESULTS}

The run-in friction of ta-C and HCF (at a very low pressure, $5^{*} 10^{-6} \mathrm{~Pa}$ ) is presented in Fig.1. As can be seen, the friction coefficient of ta-C increased from an initial 0.3 to a steady state value $>0.6$. Showing a completely different behavior, HCF started off at $\approx 0.2$ and fell within 100 revolutions to $\approx 0.01$. It was interesting to see the two materials start off at approximately the same friction, only to diverge during the progress of the experiment.

The addition of water vapor yielded quantitative as well as qualitative changes. For ta-C, two examples are presented in Fig. 2 . At $\approx 3 \mathrm{~Pa}$, the average friction coefficient is just above 0.2 and there is a pronounced element of stick-slip. Increasing the pressure to $2000 \mathrm{~Pa}$ reduced friction to 0.07 and the frictional behavior became very steady. 
Friction curves for $\mathrm{HCF}$ at three pressures are presented in Fig. 3. At $0.4 \mathrm{~Pa}$, the friction coefficient is 0.02 and at $460 \mathrm{~Pa}$ it has increased to 0.035 . In both cases, the friction curve is rather smooth. Increasing the pressure to $2000 \mathrm{~Pa}$ increased friction to 0.08 , and the friction curve is much less steady.

A compilation of 17 pin-on-disc experiments on ta-C at various pressures is given in Fig. 4. The graph is presented as lin-log to facilitate the appreciation of low-pressure behavior. From approximately $\approx 100 \mathrm{~Pa}$ and up, the friction coefficient was constant and in the range of 0.05 to 0.08 .

Figure 5 is the summary of 15 experiments on HCF under varying pressure. Again, the HCF coating showed the reverse response when compared with ta-C. Plot 5a emphasizes the low-pressure behavior, whereas plot $5 \mathrm{~b}$ emphasizes the behavior above $100 \mathrm{~Pa}$. Below $100 \mathrm{~Pa}$, the friction was constant at or below 0.02, whereas above $100 \mathrm{~Pa}$, it increased in an approximately linear fashion.

A comparison of the behavior of the two materials under varying pressure is provided in Fig. 6, where both axes are log-scales to facilitate resolution in the large range of friction and pressure. The low friction of the $\mathrm{HCF}$ and the high friction of ta-C under low pressures are obvious, as are the linear increase of HCF friction and a constant ta-C friction above $100 \mathrm{~Pa}$. In addition, note how close to the water vapor pressure the friction of the two materials became similar.

The wear was not quantified; however, the experiments were limited to only 100 revolutions because the ta- $\mathrm{C}$ film on the ball was worn through after 200 revolutions in vacuum. On the other hand, no wear could be seen on the HCF-coated ball after 100 revolutions in vacuum, although minute amounts of debris indicated the flat had been slightly worn.

\section{DISCUSSION}

The results presented above indicated that the two carbon-based films used in our studies, ta-C and HCF exhibit very different frictional behavior in vacuum and in the presence of water vapor. Only close to the water condensation pressure do they give a 
similar frictional response. The high intrinsic (i.e., in the absence of gas molecules) friction of ta-C is effectively reduced by water, i.e., water provides an extrinsic reduction of friction. For the HCF film, water destroys the intrinsic superlow friction, i.e., water provides an extrinsic increase in friction. Clearly, water exerts profound effects on the frictional behavior of both types of coatings. Over the investigated range of the water vapor pressure, the friction was changed one order of magnitude for each film.

The friction of ta-C was greatly decreased with even minute amounts of water (Fig. 2). Already at $1 \mathrm{~Pa}$ of water vapor, corresponding to $0.04 \%$ relative humidity at room temperature, the friction of ta-C is halved. Given the difficulty in determining low levels of atmospheric moisture accurately with standard humidity meters, this could explain the variations in friction coefficients of ta-C films in "dry" environments.

The superlow friction behavior of HCF in inert test environments has been attributed to the very low adhesive forces between fully hydrogen-terminated sliding surfaces of these carbon coatings [16]. We believe that the situation will be similar or essentially the same in high vacuum. Water molecules adsorbed to these surfaces could change the interaction to dipolelike, increasing the adhesive forces and hence friction. Even more water would initiate a viscous drag and still more capillary forces. This could explain the linear increase of friction with pressure from $100 \mathrm{~Pa}$ to the water condensation pressure. Hence, the friction between the two coatings could increase without the action of phase transformations or the involvement of third bodies in the presence of water molecules. However, to justify this line of reasoning, the amount of water on the surface at various pressures must first be known. However, Donnet et al [17] find that the friction of DLC in a water vapor environment is associated with the presence or absence of a carbon transfer film.

Savage [1] measured friction between graphite and copper and noted that "the high friction coefficient ( $\mu=80$ percent) which had persisted in vacuum showed an immediate drop" as water was added to the system. He saw no effect on friction from adding nitrogen or carbon monoxide, only a small effect from oxygen, but large effects from "the easily condensable vapors" such as ammonia, acetone, benzene, and ethanol. 
He attributed the friction reduction to the reduced sliding-interface cohesion of graphite caused by a transient surface coverage of potential cross-interface bonds. Adopting the ideas of Savage, one could speculate that high-friction surface sites exist on the ta-C surface, and that these sites can be passivated or effectively neutralized by the adsorption of water molecules. Because only a few layers of water may be required to separate the high-friction surfaces, water can offer substantial reduction of friction in very low pressures of water vapor. However attractive, this idea leaves out the role of third bodies, because implicit in this line of reasoning is an essentially monomolecular sliding-velocity accommodation interface. Because, at least in low humidity, there is wear of the ta-C film, third bodies are likely to influence the frictional behavior, rendering this picture too simplistic. Yet another part of the explanation of the observed phenomena could concern tribochemical reactions. In the presence of water, the formation of various organic groups (alcohol, carbonyl, carboxyl, etc.) could govern or influence the friction between the carbon surfaces. At this stage of the investigation, there is no proof excluding the effect of either of these contributions.

At higher water vapor pressures, presumably from $100 \mathrm{~Pa}$ and up, more water should be present on the surface and the effect of viscous drag and capillary forces may be the dominant contributors to friction. This could explain the similarity of friction coefficients of both samples ta-C and $\mathrm{HCF}$ when tested at pressures that are close to the water condensation pressure.

\section{CONCLUSIONS}

- Water molecules have large and differing effects on the friction of both tetrahedral amorphous carbon films (ta-C) and hydrogenated carbon (HCF) films.

- The friction of ta-C is halved from its vacuum level at a water vapor pressure of $1 \mathrm{~Pa}$ ( $0.04 \%$ relative humidity at room temperature), and is decreased an order of magnitude at $100 \mathrm{~Pa}$ of water vapor (4\% relative humidity).

- Water molecules destroy the superlow friction of HCF. 
- To elucidate the governing mechanisms, a more thorough analysis of the sample surface (adsorbates, intermolecular interactions, third bodies, and phase transformations) is needed.

\section{ACKNOWLEDGMENTS}

This work was supported by the U.S. Department of Energy, Office of Science, under Contract W-31-109-Eng-38. Further support was provided by the Swedish

Foundation for International Cooperation in Research and Higher Education (STINT).

\section{REFERENCES}

1. R. Savage, J. Appl. Phys., 19 (1948) 1.

2. $\quad$ F. P. Bowden and J. E. Young, Proc. Royal Soc., London, 208 (1951) 444.

3. F. P. Bowden and A. E. Hanwell, Proc. Royal Soc., London, A295 (1966) 233.

4. $\quad$ M. N. Gardos and B. L. Soriano, J. Mater. Res., 5 (1990) 2599.

5. A. Erdemir, M. Switala, R. Wei, and P. Wilbur, Surf. Coat. Technol., 50 (1991) 17.

6. Y. Liu, A Erdemir, and E. I. Meletis, Surf. Coat. Technol., 94-95 (1997) 463.

7. A. Erdemir, O.L. Eryilmaz, and G. Fenske, J. Vac. Sci. Technol., A 18(4) (2000) 1987.

8. C. Donnet, J. Fontaine, T. Le Mogne, M. Belin, C. Heau, J. P. Terrat, F. Vaux, and G. Pont, Surf. Coat. Technol., 120-121 (1999) 548.

9. A. Erdemir, O. L. Eryilmaz, Y. B Nilufer, and G. R Fenske, Diam. Rel. Mater., 9 (2000) 632.

10. C. Donnet, A. Grill, Surf. Coat. Technol., 94-95 (1997), 456.

11. A. A. Voevodin, J. P. O’Neill, and J. S. Zabinski, Surf. Coat. Technol., 116-119 (1999) 36.

12. R. L. C. Wu, A. K. Rai, and K. Miyoshi, Appl. Phys. Lett., 68 (1996) 1054.

13. R. Gilmore and R. Hauert, Thin Solid Films, 398-399 (2001) 199.

14. J. A. Heimberg, K. J. Wahl, I. L. Singer, and A. Erdemir, Appl. Phys. Lett., 78 (17) (2001) 2449. 
15. R. H. Horsfall, Proceedings of the 41st Annual Technical Conference, Society of Vacuum Coaters, April 18-23 1998, Boston, MA, USA, Society of Vacuum Coaters, Albuquerque, NM USA pp. 60-65.

16. A. Erdemir, Surf. Coat., Technol. 146-147 (2001) 292.

17. C. Donnet, T. Le Mogne, L. Ponsonnet, M. Belin, A. Grill, V. Patel, and C. Jahnes, Tribology Lett., 4, (1998) 259. 


\section{FIGURE CAPTIONS}

Fig. 1. Frictional behavior of ta-C and $\mathrm{HCF}$ in high vacuum.

Fig. 2. Frictional behavior of ta-C at two water vapor pressures.

Fig. 3. Frictional behavior of HCF at three different water vapor pressures.

Fig. 4. Effect of water vapor pressure on frictional behavior of ta-C.

Fig. 5. Frictional behavior of HCF at differing water vapor pressures. (a) Lin-log plot showing frictional behavior at low water vapor pressures and (b) Lin-lin plot showing general frictional behavior over a wide range of water vapor pressures

Fig. 6. Summary of frictional behavior of ta-C (open diamonds) and HCF (filled squares) as a function of water vapor pressure. 


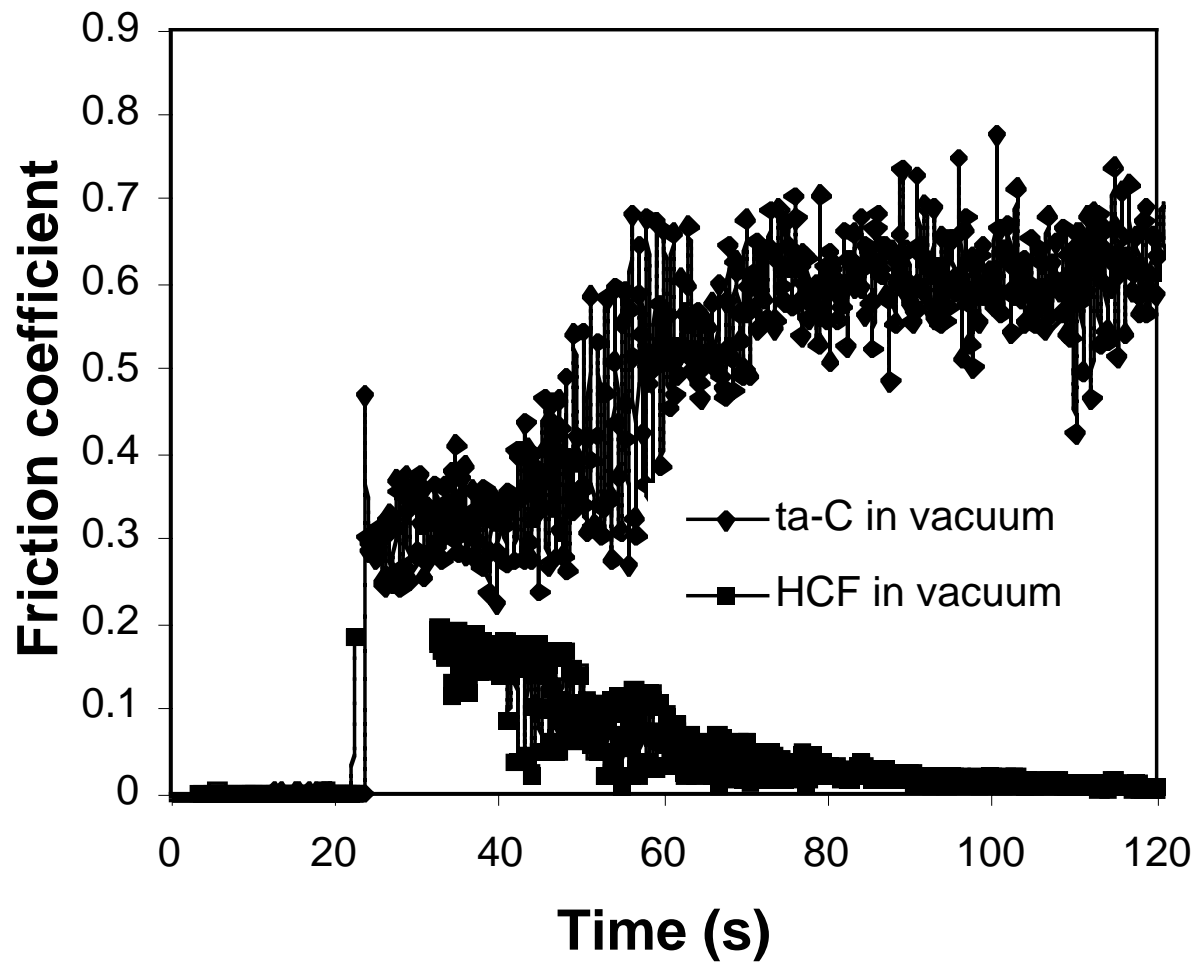

Fig. 1. 


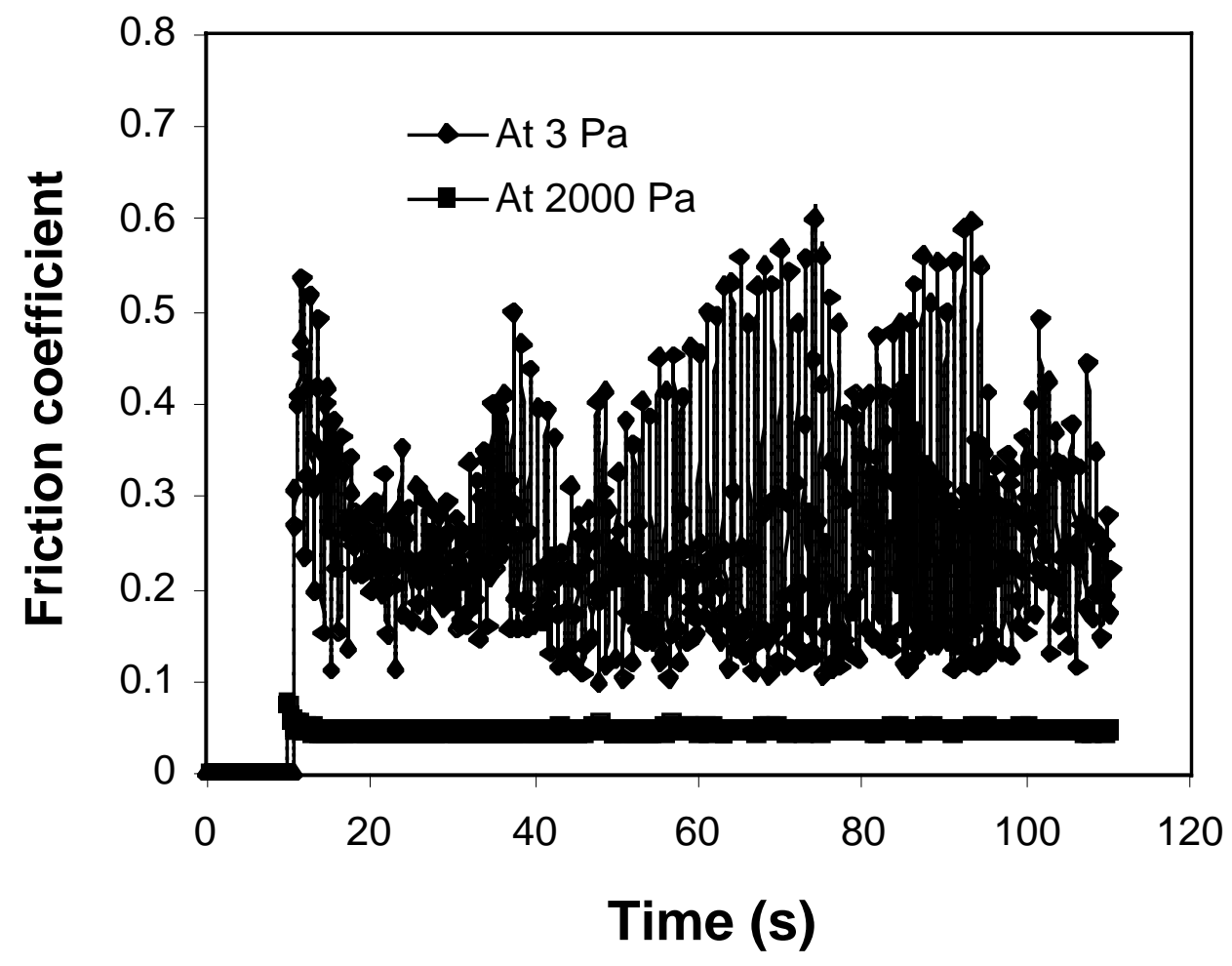

Fig. 2. 


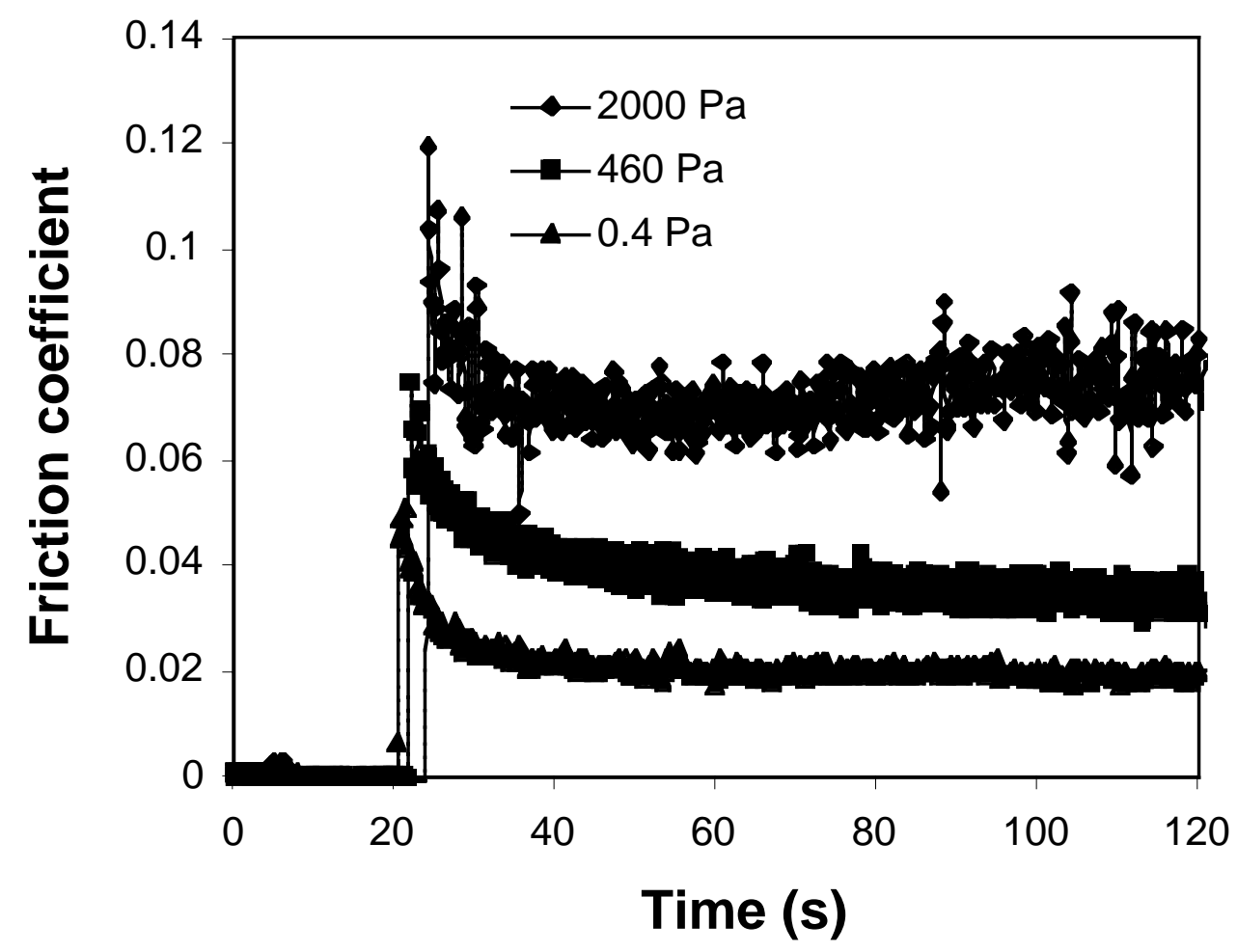

Fig. 3. 


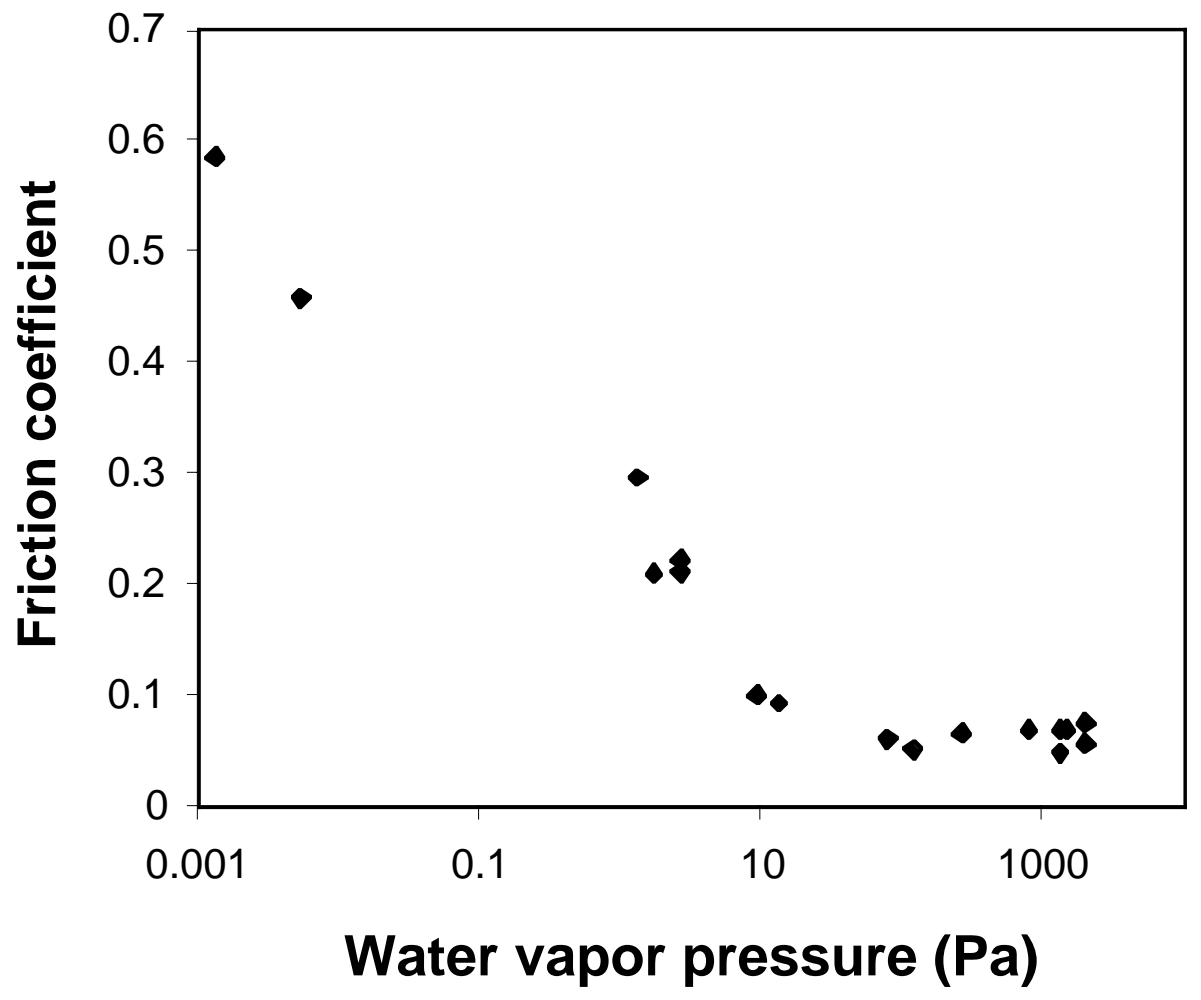

Fig. 4. 
a)

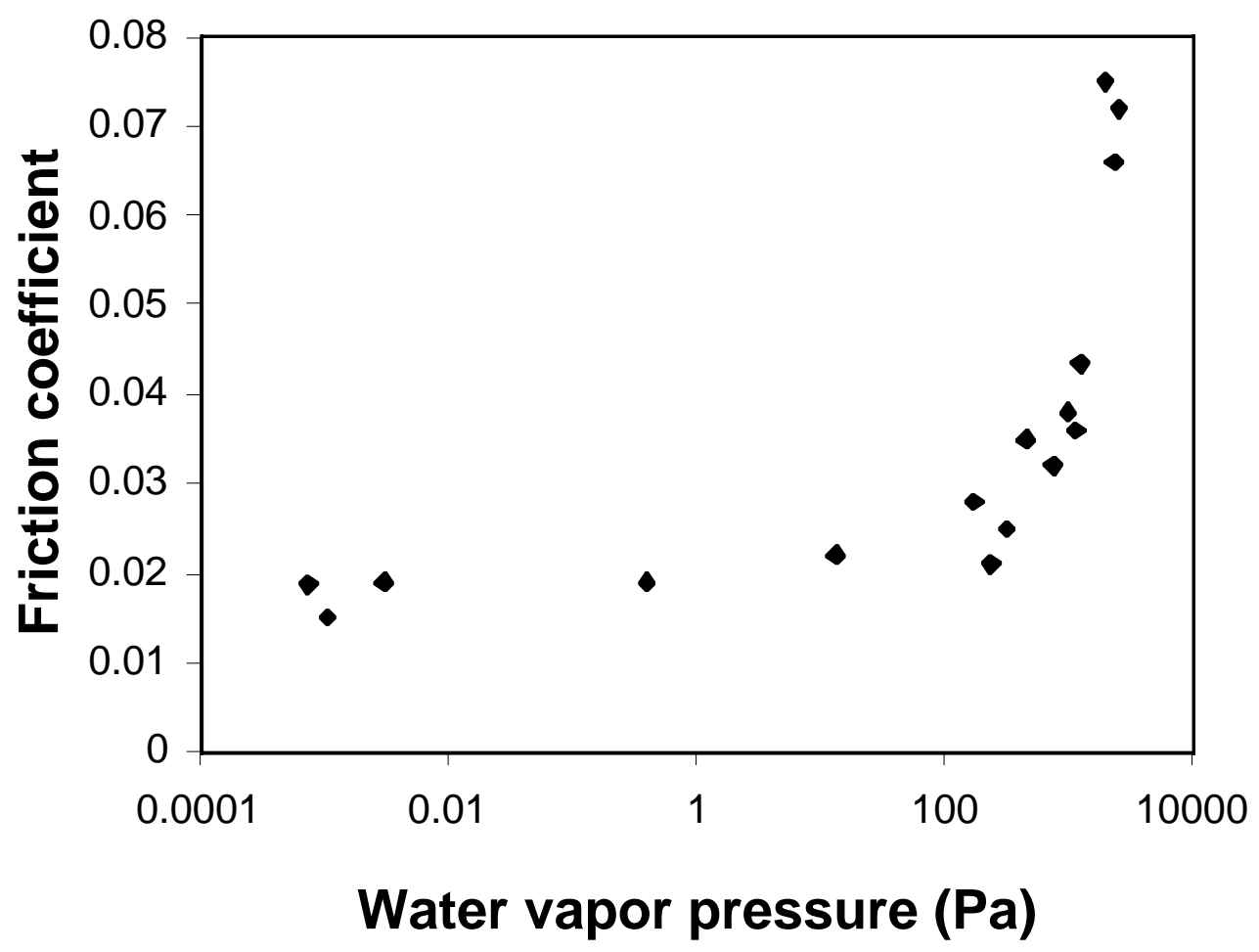

b)

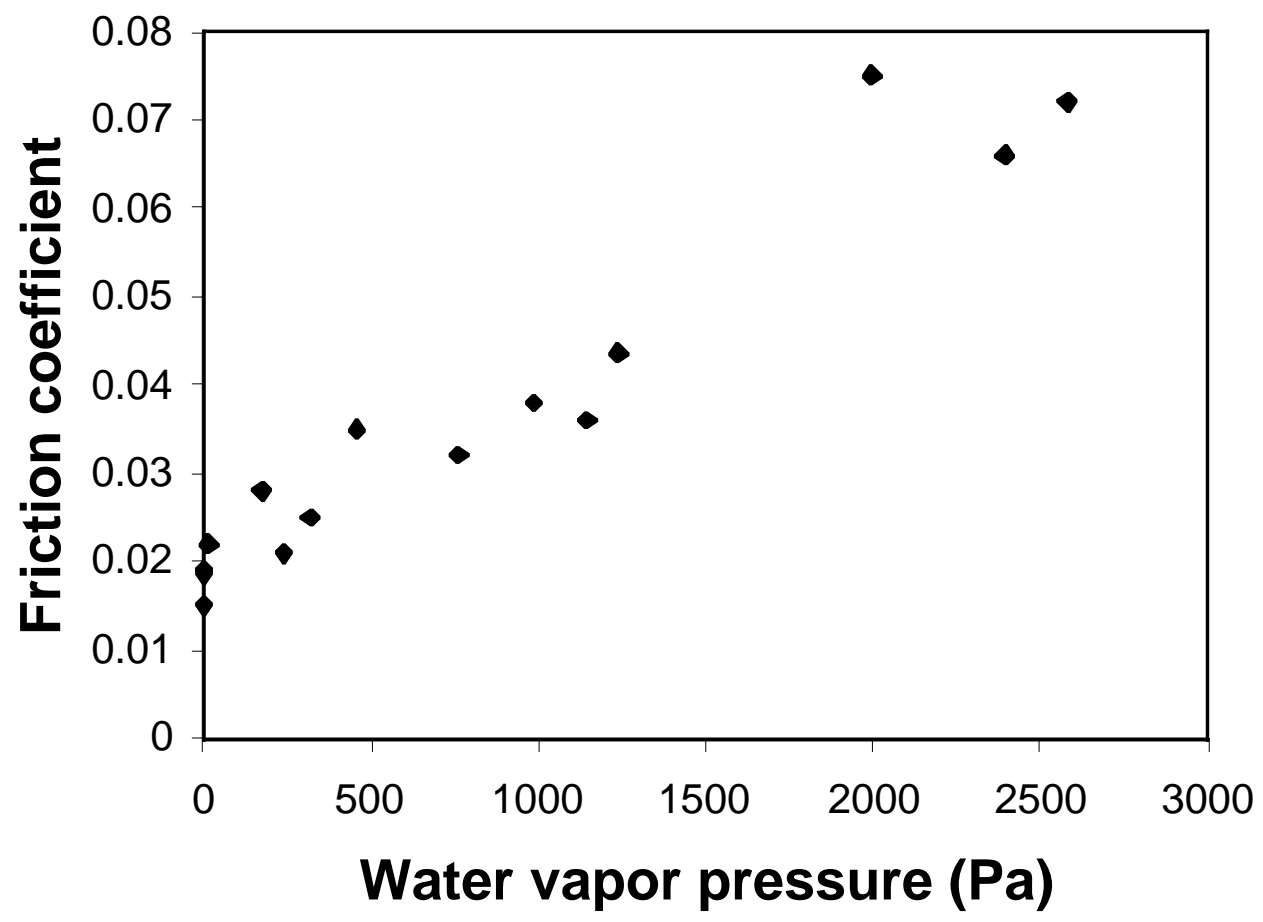

Fig. 5. 


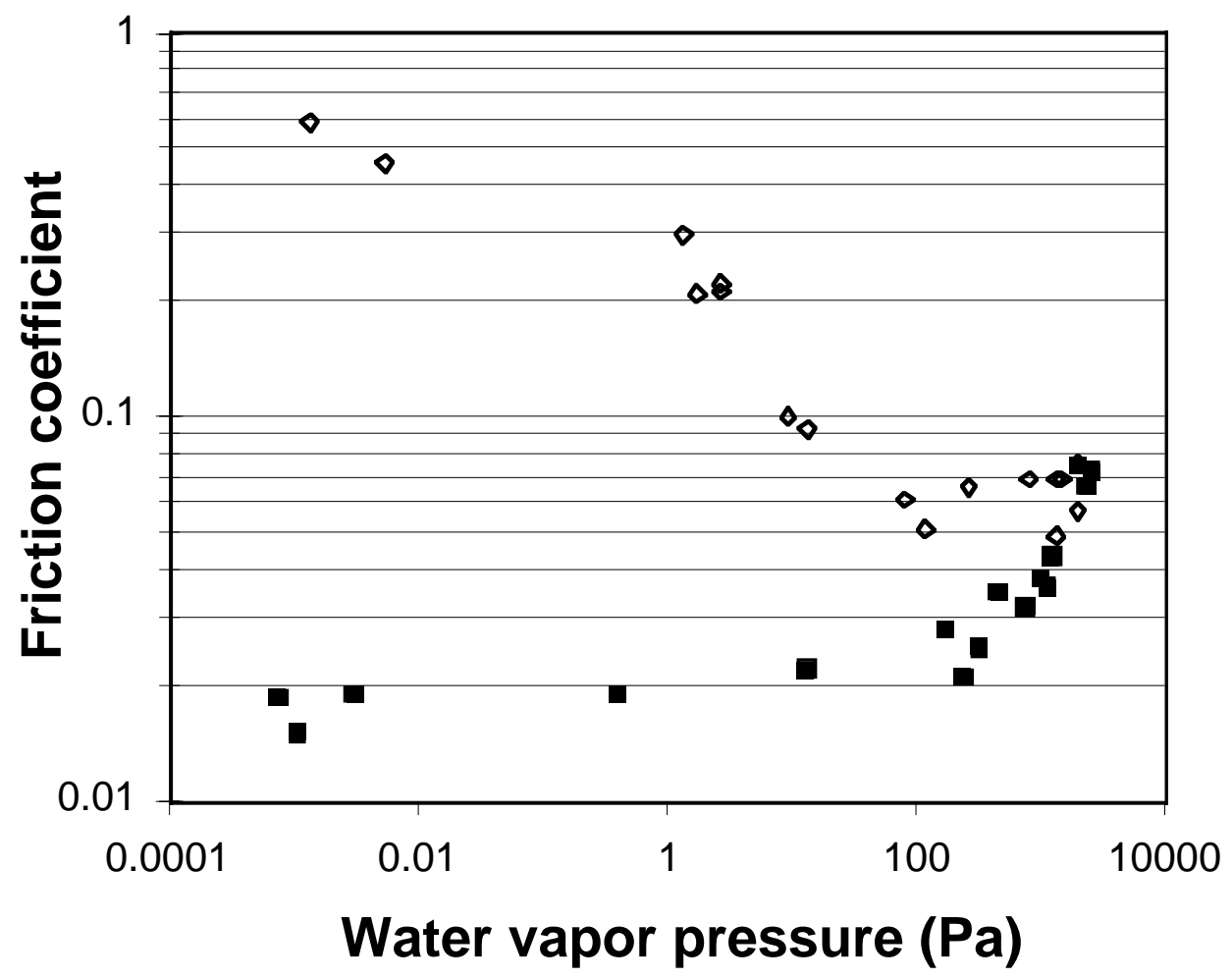

Fig. 6. 